\title{
Short Communication: The bioinformatics perspective of Foeniculum vulgare fruit's bioactive compounds as natural anti-hyperglycemic against alpha-glucosidase
}

\author{
FATCHUR ROHMAN ${ }^{1, \boldsymbol{v}}$, WIRA EKA PUTRA ${ }^{1,2}$ \\ ${ }^{1}$ Department of Biology, Faculty of Mathematics and Natural Sciences, Universitas Negeri Malang. Jl. Semarang No. 5, Malang 65145, East Java, \\ Indonesia. Tel.: +62-341-567382, ”email: fatchur.rohman.fmipa@um.ac.id \\ ${ }^{2}$ Department of Biotechnology, Faculty of Mathematics and Natural Sciences, Universitas Negeri Malang. Jl. Semarang No. 5, Malang 65145, East Java, \\ Indonesia
}

Manuscript received: 1 November 2020. Revision accepted: 10 December 2020.

\begin{abstract}
Rohman F, Putra WE. 2021. Short Communication: The bioinformatics perspective of Foeniculum vulgare fruit's bioactive compounds as natural anti-hyperglycemic against alpha-glucosidase. Biodiversitas 22: 79-84. The management in controlling the blood glucose level is crucially necessary to be promoted. Many reports showed the harmful effect of glucose toxicity, most of them are the cluster of metabolic disorder. Nowadays, natural products are getting much attention on health issues. The uses of medicinal plants for drug materials are dramatically increasing. In our previous study about local medicinal plants identification, we found that Tengger Tribe in Indonesia uses numerous type of species, including Foeniculum vulgare which was widely found and occupied as traditional medicine by Tengger Tribe in the area of Taman Nasional Bromo Tengger Semeru, East Java, Indonesia. According to their local belief, $F$. vulgare has been used to ameliorate several types of diseases. Thus, in this present study, we aimed to virtually evaluate the bioactive compounds of $F$. vulgare for anti-hyperglycemic against the alpha-glucosidase. We performed computational prediction of ligandsprotein interaction by molecular docking approaches. The 2D structure of ligands and 3D structure of target protein were retrieved via the database. The natural compound's structure was then evaluated by the Lipinski rule of five to indicate whether it can be categorized as drug-like or not. Moreover, according to our simulation, F. vulgare fruit's bioactive compounds including sterol, anethole, and fenchone might have therapeutic effect to reduce the hyperglycemia incidence by inhibiting the alpha-glucosidase activity. Compared to miglitol, an alpha-glucosidase inhibitor, Sterol have the most significant binding affinity against the alpha-glucosidase. Therefore, these findings suggest that sterol, anethole, and fenchone might be potential new candidates for alpha-glucosidase inhibitors.
\end{abstract}

Keywords: Foeniculum vulgare, in silico, hyperglycemia, medicinal plant, Tengger Tribe

\section{INTRODUCTION}

Owing to increased obesity, reduced physical activity levels, and an aging population, the incidence of hyperglycemia has increased significantly over the last two decades. Between men and women, the prevalence is similar (Mouri and Badireddy 2020). The incidence of high plasma glucose levels often followed by complex heterogeneous metabolic disorders, including type 2 diabetes mellitus (T2DM), cardiovascular diseases (CVD), stroke, or other organ complications (Hanefeld and Schaper 2017; Fofié et al. 2018). Moreover, the long term hyperglycemic state drives to chronic conditions, causing more severe effects such as pancreatic $\beta$ cells and vascular endothelial cells damage. The damage in the pancreatic $\beta$ cells leads to insulin synthesis and secretion impairment, also the deterioration in vascular endothelial cells possibly causing the other complication related to diabetes mellitus including neuropathy, retinopathy, and nephropathy (Campos 2012). More important, persons with hyperglycemia's depends on how blood glucose levels are treated. Chronic hyperglycemia can cause serious life-and limb-threatening complications. Lifestyle improvements, daily physical exercise, and diet changes are the keys to a better forecast. Individuals who maintain euglycemia have substantially improved prognosis and quality of life relative to individuals who remain hyperglycemia. If the hyperglycemia problems have formed, they are essentially permanent. Countless studies have shown that uncontrolled hyperglycemia significantly reduces survival and impairs the quality of life (Mouri and Badireddy 2020).

Management to suppress the incidence of hyperglycemia might be one of prospective strategies to avoid the negative effect of metabolic disorder conditions like T2DM, CVD, or other complications. The initial management option for patients with hyperglycemia and catabolic symptoms, including weight loss, is insulin therapy. Importantly, therapy with physiologic doses of insulin is advised after adequate hydration (Chao and Hirsch 2018).

On the other hand, several other treatments have been proposed to minimize the impact of glucose toxicity through daily exercise, insulin treatment, or alphaglucosidase inhibitor administration (Riddell and Perkins 2009; McDonnell and Umpierrez 2012; Ouassou et al. 2018). However, the awareness and proper scheme to inhibit the elevation of plasma glucose levels are necessary to promote. This present study virtually evaluates the bioactive compounds from $F$. vulgare fruit as a natural inhibitor candidate for alpha-glucosidase. We hypothesized that the bioactive compounds from $F$. vulgare fruit might 
have inhibitory properties and a common alpha-glucosidase inhibitor to reduce the hyperglycemia incidence.

In recent years, an increasing interest was shown in naturally phenolic compounds. Several of them are found in plants, and the consumption of vegetables and drinks with a high level can help prevent many diseases through their ameliorative properties (Giada 2013). Natural products get more attention especially in health and medical issues. The uses of natural products as the primary material for drug development are assumed to be safer compared to synthetic materials (Ekor 2013; Karimi et al. 2015). Indonesia is considered a mega biodiversity country with more than thousands of plant species occupied as building materials, food, industry, animal feed, or medical source. Interestingly, the group of people in Taman Nasional Bromo Tengger Semeru (TNBTS) has been employed by the local plants for a broad spectrum of purposes, especially for medical materials. Our previous study about medicinal plant identification found that $F$. vulgare has the highest index of cultural significance value about $78.36 \%$ overall the plant species and is widely spread in the TNBTS area. Interestingly, the Tengger tribe also used this plant for a food source and medicinal purposes such as cough medicine (Rohman et al. 2019).

\section{MATERIALS AND METHODS}

In this study, we performed computational prediction of ligands-protein interaction to screen the potency of several bioactive compounds from $F$. vulgare fruits, including sterol, anethole, fenchone, and estragole. The 2D structure of each compound was retrieved from the PubChem database (https: //pubchem.ncbi.nlm.nih.gov/). Moreover, Miglitol, an alpha-glucosidase inhibitor, was used as a controlled drug. PubChem has been one of the main and large public archives for data on the biological activities of chemical substances. Since 2004, PubChem has increasingly become a crucial chemical information platform for the large scientific community in a wide number of research areas such as pathophysics, engineering, medicinal chemistry, and drug development under the National Institute of Health, United States of America. PubChem is one of the main classes of information on chemical products publicly available. More than 157 million descriptions of chemical materials, 60 million typical chemical structures, and 1 million bioassay descriptions were provided, covering around 10 thousand unique target protein sequences (Kim et al. 2016).

Further, the 3D structure of alpha-glucosidase was constructed through SWISS-MODEL web server (https: //swissmodel.expasy.org/). SWISS-MODEL is a web-based integrated protein structure modeling service. It helps and guides the user in designing models for protein structure and its homology at various levels of complexity. Resources are accessible from inside the comfortable and accessible workstation for choosing numerous configurations, models, and quality assessment of the protein structure (Arnold et al. 2006).
Lipinski rule of five was used as standard evaluation to decide whether the compounds have potency as drug-like molecules. According to the indicators, the small molecule has to have molecular mass of no more than 500 Dalton, high lipophilicity no more than five, molar refractivity about 40 to 130 , no more than five hydrogen bond donors, and no more than ten hydrogen bond acceptors (Lipinski 2004). All small molecules and target proteins were optimized before processed via computational prediction. Further, the modeling, molecular docking, and visualization step were performed as similar protocol with our previous study (Putra et al. 2019, 2020; Putra and Rifa'i 2020).

\section{RESULTS AND DISCUSSION}

Hyperglycemia is a multiple and accumulative consequence of genetic, environmental, and immunologic influences in a patient with T1DM. These factors contribute to the degradation and insulin deficiency of pancreatic beta cells. Insulin resistance and abnormal insulin secretion contribute to hyperglycemia in patients with T2DM. Reduced insulin release, reduced glucose utilization, and elevated glucose production are factors leading to hyperglycemia. Glucose homeostasis is a balance between the production of hepatic glucose and the absorption and consumption of peripheral glucose. The most important regulator for glucose balance and homeostasis is insulin. In addition, the following are the secondary causes of hyperglycemia such as degradation of the pancreas due to chronic pancreatitis, hemochromatosis, pancreatic cancer, and cystic fibrosis; use of medicines such as glucocorticoids, phenytoin, and estrogens; and endocrine malfunction, which cause peripheral insulin resistance such as Cushing syndrome, acromegaly, and pheochromocytoma (Mouri and Badireddy 2020).

Hyperglycemia is one of the risk factors of T2DM (Wu et al. 2014; Bowen et al. 2015). Inhibiting the incidence or lower the negative effect of hyperglycemia can minimize the adverse prognosis of T2DM patients. Alphaglucosidase has crucial role in carbohydrate metabolism, this enzyme can convert the carbohydrate into glucose (Scheen 2003; Hanefeld and Schaper 2017). In T2DM patients, the cells fail to occupy and transform the glucose into energy because of insulin resistance, therefore glucose remains high in the blood. Targeting the alpha-glucosidase with the small compounds is one of the strategies to suppress glucose level in blood.

Foeniculum vulgare is an umbellum herb commonly used as a food and for medicinal purposes. Plant seeds of this species have been shown to control menstrual cycles, relieve symptoms, and improve libido. F. vulgare also showed the potential medicinal properties in diabetes, bronchitis, and chronic coughs. Furthermore, the F. vulgare traditionally used as an antispasmodic, carminative, diuretic, stimulant to lactation and wound dressings, $F$. vulgare extract was used (Mhaidat et al. 2015). In this present study, we found that the bioactive compounds from $F$. vulgare fruit showed high potency to become anti- 
hyperglycemic agents because of their prospective binding affinity scores against the alpha-glucosidase (Figure 1). The computational prediction demonstrated sterol has the most exceptional binding affinity score $(-7.3 \mathrm{kcal} / \mathrm{mol})$ followed by Anethole $(-5.8 \mathrm{kcal} / \mathrm{mol})$, Fenchone $(-5.7$ $\mathrm{kcal} / \mathrm{mol})$, and Miglitol $(-5.7 \mathrm{kcal} / \mathrm{mol})$ as the control drug (Figure 2). The more negative of binding affinity scores means the ligand has favorable and stable interaction to the target protein (Atkin and Paula 2006).
(A)
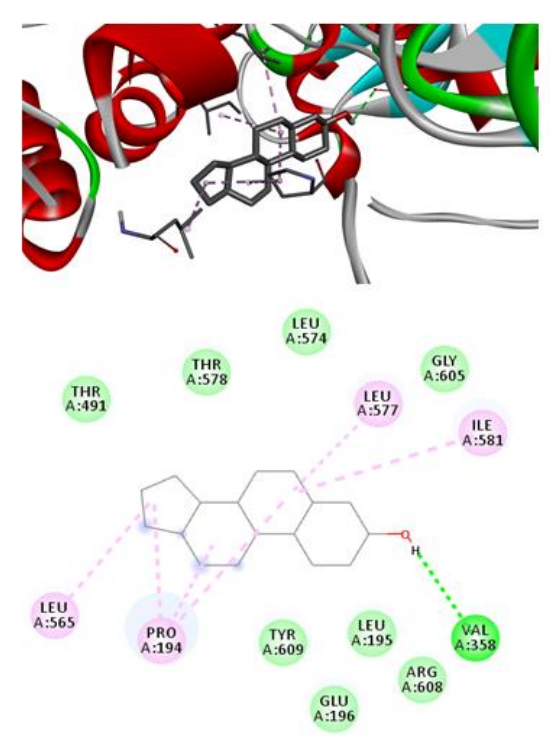

Interactions

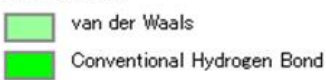

Conventional Hydrogen Bond

\section{(c)}
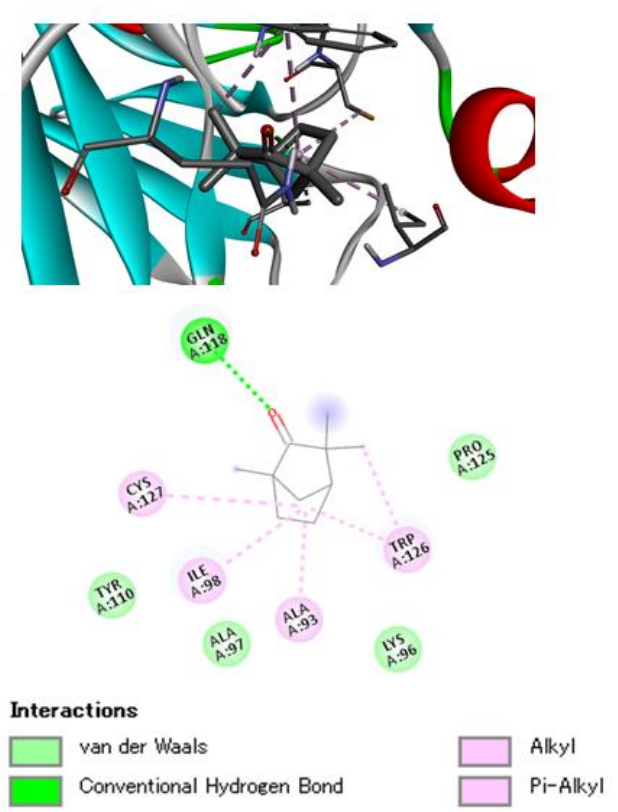

B
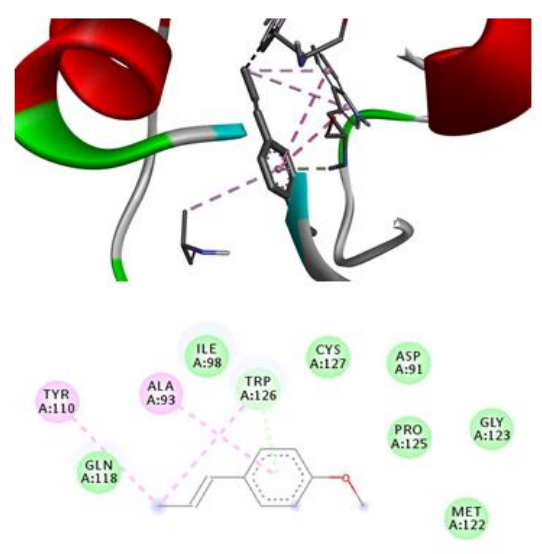

Interactions

van der Waals

Pi-Donor Hydrogen Bond

Pi-Pi Stacked Pi-Alkyl

(D)
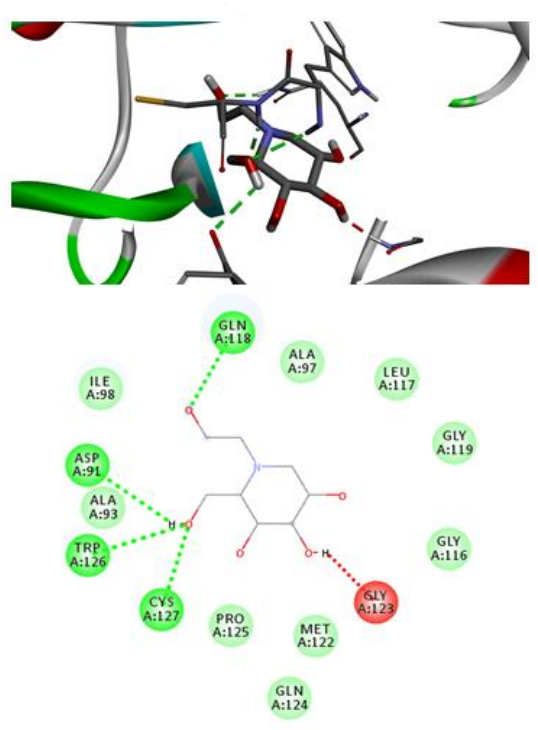

van der Waals

Conventional Hydrogen Bond

Unfavorable Donor-Donor

Figure 1. Molecular docking results showed the interaction between target protein and ligands, including alpha-glucosidase - sterol (A), alpha-glucosidase - anethole (B), alpha-glucosidase - fenchone (C), and alpha-glucosidase - miglitol (D). 


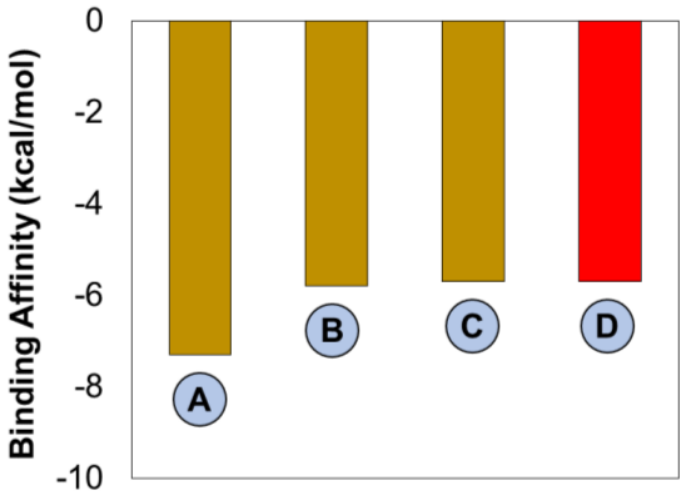

Protein - Ligand Interaction

A Van der Waals: THR A:491, THR A:578, LEU A:574, GLY A:605, LEU A:195, ARG A:608, GLU A:196, TYR A:609

Alkyl: LEU A:577, ILE A:581, PRO A:194, LEU A:565

Conventional Hydrogen Bond: VAL A:358
(B) Van der Waals: GLN A:118, ILE A:98, CYS A:127, ASP A:91, PRO A:125, GLY A:123, MET A:122

Pi-Donor Hydrogen Bond: TRP A:126

Pi-Alkyl: TYR A:110, ALA A:93

Van der Waals: TYR A:110, ALA A:97, LYS A:96, PRO A:125

Pi-Alkyl: CYS A:127, ILE A:98, ALA:93, TRP A:126

Conventional Hydrogen Bond: GLN A:118

Van der Waals: ILE A:98, ALA A:97, LEU A:117, GLY A:119, GLY A:116, MET A:122, GLN A:124, PRO A:125, ALA A:93

Conventional Hydrogen Bond: CYS A:127, TRP A:126, ASP A:91, GLN A:118

Unfavorable Donor-Donor: GLY A:123

Figure 2. Binding affinity and chemicals interaction between ligand and protein, alpha-glucosidase - sterol (-7.3 kcal/mol) (A), alphaglucosidase - anethole (-5.8 kcal/mol) (B), alpha-glucosidase - fenchone (-5.7 kcal/mol) (C), and alpha-glucosidase - miglitol (-5.7 $\mathrm{kcal} / \mathrm{mol})(\mathrm{D})$.

On the other hand, we demonstrated that almost all ligands - target protein complexes have van der Waals interaction. Further, other interactions that distinguished each ligand-protein group are alkyl and conventional hydrogen bond interaction in alpha-glucosidase - sterol complex; pi-donor hydrogen bond and pi-alkyl in alphaglucosidase - anethole complex; pi-alkyl and conventional hydrogen bond in alpha-glucosidase - fenchone complex; and conventional hydrogen bond in alpha-glucosidase miglitol complex (Figure 2). These chemicals interaction is needed to determine the complex of ligand-target protein characters and maintain the molecular interaction, stability, and dynamics (Chen et al. 2013; Chen et al 2015). Hydrogen bonds are relatively weak interactions that are, however, important for biological macromolecules. Hydrogen bonding, an interaction of the hydrogen atom occurring between a pair of other atoms with a high affinity for electrons; such a bond is weaker than an ionic or covalent bond, but stronger than van der Waals' powers. Hydrogen bonds can exist between atoms in various molecules or in parts of the same molecule. These partnerships have many of the properties of water that make it such a special solvent. The hydrogen atom is partly split into two relatively electronegative atoms inside a hydrogen bond, such as nitrogen and oxygen. The donor of hydrogen bonds consists of both the atom linked to hydrogen and hydrogen itself; the atom linked to hydrogen is not closest to the atom linked to hydrogen. The atom is the atom that bundles hydrogen. Hydrogen relations are essentially electrostatic interactions (Berg et al. 2002).

Foeniculum vulgare is one of the species that commonly used as traditional medicine by common people, especially by Tengger tribe. According to our previous study about medicinal plant identification, we got $F$. vulgare easy to find and grow abundantly in the area of Bromo Tengger National Park (Rohman et al. 2019). A lot of studies have been revealed that $F$. vulgare contains several bioactive compounds, namely sterol, anethole, fenchone, and estragole (Budianto et al. 2015). Thus, from those benefit, $F$. vulgare often used to ameliorate several types of diseases such as hepatoprotective activities, antioxidant, antibacterial, antithrombotic, and antifungal (Rather et al. 2016).

Obviously, from three of bioactive compounds found in the $F$. vulgare, sterol has the most significant binding affinity compared to anethole or fenchone. Here, in this report, we also showed the properties of sterol as inhibitory drug candidate against the alpha-glucosidase which include physicochemical properties, drug-likeness, chemical structures and the target class of protein (Figure 3). Sterol is known as steroid alcohol, which commonly used as medicine because of its therapeutic potencies such as lowering plasma cholesterol and LDL cholesterol, anticancer, anti-inflammatory, and anti-oxidant (Piironen et al. 2000; Berger et al. 2004). Another study conducted by Brüll and Mensink (2009), showed the activity of sterol in decreasing the response of Th1, increasing Th2 regulation, and suppressing the inflammation incidence (Brüll and Mensink 2009). In the field of cancer, several studies demonstrated that sterol has great potency to be protective agents against lung, breast, or stomach cancer (Mendilaharsu et al. 1998; Ronco et al. 1999; De Stefani et al. 2000). 


\section{Physicochemical Properties}

\begin{tabular}{ll}
\hline Formula & $\mathrm{C} 17 \mathrm{H} 28 \mathrm{O}$ \\
Molecular weight & $248.40 \mathrm{~g} / \mathrm{mol}$ \\
Num. heavy atoms & 18 \\
Num. arom. heavy atoms & 0 \\
Fraction Csp3 & 1.00 \\
Num. rotatable bonds & 0 \\
Num. H-bond acceptors & 1 \\
Num. H-bond donors & 1 \\
Molar Refractivity & 76.54 \\
TPSA $(2)$ & $20.23 \AA^{2}$
\end{tabular}

\section{Druglikeness}

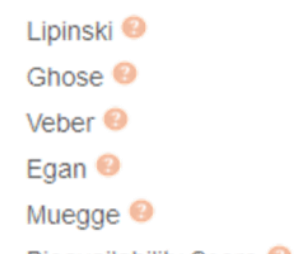

Bioavailability Score 2

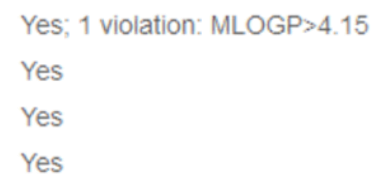

No; 2 violations: XLOGP3 $>5$, Heteroatoms $<2$ 0.55
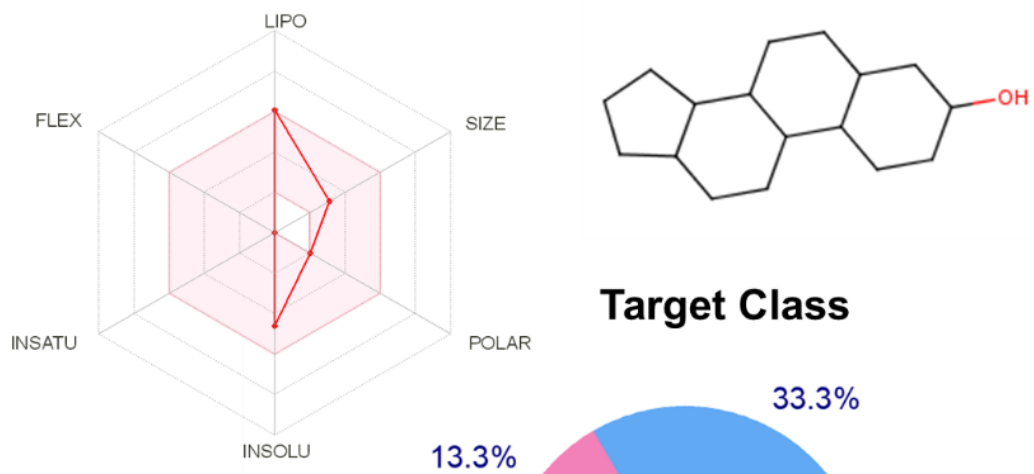

\section{Target Class}

$33.3 \%$

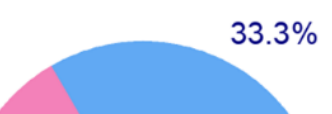

$13.3 \%$

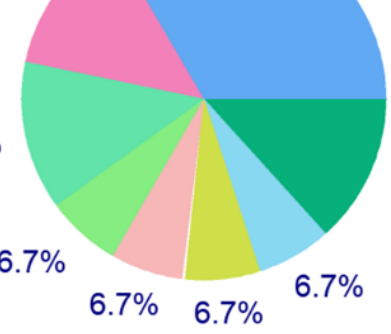

$13.3 \%$

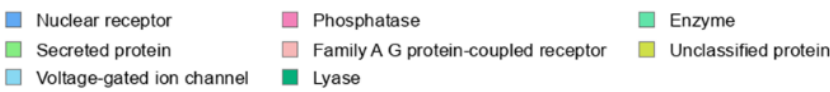

Enzyme

Figure 3. The properties of sterol as potential inhibitory drug candidate for alpha-glucosidase. Several properties showed including the physicochemical properties, drug-likeness, chemical structures and also the target class of protein

On the other hand, sterol has been known as suppressor factor which can lower the level of low-density lipoprotein and triglycerides. The biological effect of sterol, in this case, may also decrease the risk of T2DM incidence or any other metabolic syndromes (Lau et al. 2005; Trautwein et al. 2018; Baker et al. 2019). Furthermore, it has been narrated that sterol also showed hypoglycemic properties by lowering the glucose level in blood and increasing the level of insulin of rat model for hyperglycemic after administrated by $\beta$-sitosterol (Zakłos-Szyda 2015). Even though, there is evidence about how sterol lowering the glucose level, however the mechanism of action still on very limited information. Therefore, we assume that the hypoglycemic properties of sterol might be related to its inhibition activity against alpha-glucosidase as what we have predicted in above explanation.

Finally, based on our simulation, $F$. vulgare fruit's bioactive compounds including sterol, anethole, and fenchone might have therapeutic effect to reduce the hyperglycemia incidence by inhibiting the alphaglucosidase activity. However, performing the in vitro or in vivo experiment is necessary to evaluate these compounds' efficacy and effect toward hyperglycemia condition.

\section{ACKNOWLEDGEMENTS}

The authors thank the Department of Biology and Department of Biotechnology, Faculty of Mathematics and Natural Sciences, Universitas Negeri Malang, Indonesia.

\section{REFERENCES}

Arnold K, Bordoli L, Kopp J, Schwede T. The SWISS-MODEL workspace: a web-based environment for protein structure homology modelling. Bioinformatics. 22 (2): 195-201. DOI: 10.1093/bioinformatics/bti770.

Atkin P, Paula DJ. 2006. Physical Chemistry. 8th ed. W.H. Freeman and Company, New York.

Baker WL, Baker EL, Coleman CI. 2019. The effect of plant sterols or stanols on lipid parameters in patients with type 2 diabetes: A metaanalysis. Diabetes Res Clin Pract 84: 33-37.

Berg JM, Tymoczko JL, Stryer L. 2002. Biochemistry. 5th ed.: W.H. Freeman, New York.

Berger A, Jones PJ, Abumweis SS. 2004. Plant sterols: Factors affecting their efficacy and safety as functional food ingredients. Lipids Health Dis 3: 1-19.

Bowen ME, Xuan L, Lingvay I, Halm EA. 2015. Random blood glucose: a robust risk factor for type 2 diabetes. J Clin Endocrinol Metabolism 100: 1503-1510.

Brüll F, Mensink R. 2009. Plant sterols: Functional lipids in immune function and inflammation? Clin Lipidol 4: 355-365. 
Budianto, Prajitno A, Yuniarti A. 2015. Antibacterial activity of fennel (Foeniculum vulgare Mill) extracts on Vibrio alginolyticus and Vibrio harveyi. Agritech 35: 1-7.

Campos C. 2012. Chronic hyperglycemia and glucose toxicity: pathology and clinical sequelae. Postgrad Med 124: 90-7.

Chao JH, Hirsch IB. Initial management of severe hyperglycemia in type 2 diabetes. 2018. In: Feingold KR, Anawalt B, Boyce A, et al. (eds.) Endotext. MDText.com, Inc., South Dartmouth, MA.

Chen L, Huang T, Zhang J, Zheng M, Feng K, Cai Y, Chou K. 2013 Predicting drugs side effects based on chemical-chemical interactions and protein-chemical interactions. BioMed Res Intl 2013: 485034 DOI: $10.1155 / 2013 / 485034$.

Chen L, Yang J, Zheng M, Kong X, Huang T, Cai Y-D. 2015. The use of chemical-chemical interaction and chemical structure to identify new candidate chemicals related to lung cancer. PLoS ONE 10: e0128696. DOI: 10.1371/journal.pone.0128696.

De Stefani E, Boffetta P, Ronco AL, Brennan P, Deneo-Pellegrini H, Carzoglio JC, Mendilaharsu M. 2000. Plant sterols and risk of stomach cancer: a case-control study in Uruguay. Nutr Cancer 37: 140-144.

Ekor M. 2013. The growing use of herbal medicines: issues relating to adverse reactions and challenges in monitoring safety. Fron Pharmacol 4: 1-10.

Fofié CK, Nguelefack-Mbuyo EP, Tsabang N, Kamanyi A, Nguelefack TB. 2018. Hypoglycemic properties of the aqueous extract from the stem bark of Ceiba pentandra in dexamethasone-induced insulinresistant rats. Evid-Based Compl Altern Med 2018: 4234981, DOI $10.1155 / 2018 / 4234981$.

Giada MLR 2013. Food phenolic compounds: main classes, sources and their antioxidant power, oxidative stress and chronic degenerative diseases - a role for antioxidants, José A. Morales-González, IntechOpen, UK. DOI: 10.5772/51687.

Hanefeld M, Schaper F. 2007. The role of alpha-glucosidase inhibitor (Acarbose). In: Mogensen CE. (ed.). Pharmacotherapy of Diabetes: New Developments. Springer, Boston, MA.

Karimi A, Majlesi M, Rafieian-Kopaei M. 2015. Herbal versus synthetic drugs; beliefs and facts. J Nephropharmacol 4: 27-30.

Kim S, Thiessen PA, Bolton EE, Chen J, Fu G, Gindulyte A, Han L, He J, He S, Shoemaker BA, Wang J, Yu B, Zhang J, Bryant SH. PubChem substance and compound databases. Nucleic Acids Res 44 (D1) D1202-13. DOI: 10.1093/nar/gkv951.

Lau VWY, Journoud M, Jones PJH. 2005. Plant sterols are efficacious in lowering plasma LDL and non-HDL cholesterol in hypercholesterolemic type 2 diabetic and nondiabetic persons. Amer J Clin Nutr 81: 1351-1358.

Lipinski CA. 2004. Lead- and drug-like compounds: the rule-of-five revolution. Drug Dis Today 1: 337-341.

McDonnell ME, Umpierrez GE. 2012. Insulin Therapy for the management of hyperglycemia in hospitalized patients. Endocrinol Metab Clin North Am 41: 175-201.

Mendilaharsu M, De Stefani E, Deneo-Pellegrini H, Carzoglio J, Ronco A. 1998. Phytosterols and risk of lung cancer: a case-control study in Uruguay. Lung Cancer 21: 37-45.
Mhaidat NM, Abu-Zaiton AS, Alzoubi KH, Alzoubi W, Alazab RS. 2015. Antihyperglycemic properties of Foeniculum vulgare extract in streptozocin-induced diabetes in rats. Intl J Pharmacol 11: 72-75.

Mouri MI, Badireddy M. 2002. Hyperglycemia. StatPearls Publishing, Treasure Island, FL.

Ouassou H, Zahidi T, Bouknana S, Bouhrim M, Mekhfi H, Ziyyat A, Legssyer A, Aziz M, Bnouham M. 2018. Inhibition of $\alpha$-Glucosidase, intestinal glucose absorption, and antidiabetic properties by Caralluma europaea. Evid-Based Compl Altern Med 2018: 9589472. DOI: $10.1155 / 2018 / 9589472$

Piironen V, Lindsay DG, Miettinen TA, Toivo J, Lampi A. 2000. Plant sterols: biosynthesis, biological function and their importance to human nutrition. J Sci Food Agric 80: 939-966.

Putra WE, Rifa'i M. 2020. Evaluating the molecular interaction of Sambucus plant bioactive compounds toward TNF-R1 and TRAIL$\mathrm{R} 1 / \mathrm{R} 2$ as possible anti-cancer therapy based on traditional medicine: The bioinformatics study. Sci Stud Res Chem Chem Eng Biotechnol Food Industr 21: 357-365.

Putra WE, Salma WO, Rifa'i M. 2019. Anti-inflammatory activity of sambucus plant bioactive compounds against TNF- $\alpha$ and TRAIL as solution to overcome inflammation associated diseases: The insight from bioinformatics study. Nat Prod Sci 25: 215-221.

Putra WE, Salma WO, Widiastuti D, Kismurtono M. 2020. In silico screening of peroxisome proliferator-activated receptor gamma (PPARG)-agonist from Eugenia jambolana bioactive compounds as potential anti-diabetic agent. Malaysian J Biochem Mol Biol 23: 142146.

Rather MA, Dar BA, Sofi SN, Bhat BA, Qurishi MA. 2016. Foeniculum vulgare: A comprehensive review of its traditional use, phytochemistry, pharmacology, and safety. Arabian J Chem 9: 15741583.

Riddell M, Perkins BA. 2009. Exercise and glucose metabolism in persons with diabetes mellitus: perspectives on the role of continuous glucose monitoring. J Diabetes Sci Technol 3: 914-923.

Rohman F, Juma Y, Sulisetijono, Utomo DH, Purwanto, Lestari SR, Arifah SN, Putra WE. 2019. Plants diversity as a medicinal plants by the Tengger Tribe, Bromo Tengger Semeru National Park, East Java, Indonesia. Eurasian J Biosci 13: 2293-2298.

Ronco A, De Stefani E, Boffetta P, Deneo-Pellegrini H, Mendilaharsu M, Leborgne F. 1999. Vegetables, fruits, and related nutrients and risk of breast cancer: a case-control study in Uruguay. Nutr Cancer 35: 111119.

Scheen AJ. 2003. Is there a role for alpha-glucosidase inhibitors in the prevention of type 2 diabetes mellitus? Drugs 63: 933-951.

Trautwein EA, Koppenol WP, de Jong A, Hiemstra H, Vermeer MA, Noakes M, Luscombe-Marsh ND. 2018. Plant sterols lower LDLcholesterol and triglycerides in dyslipidemic individuals with or at risk of developing type 2 diabetes; a randomized, double-blind, placebo-controlled study. Nutr Diabetes 8: 1-13.

Wu Y, Ding Y, Tanaka Y, Zhang W. 2014. Risk factors contributing to type 2 diabetes and recent advances in treatment and prevention. Intl $\mathrm{J}$ Med Sci 11: 1185-1200.

Zakłos-Szyda M. 2015. Phytosterols in type 2 diabetes and obesity molecular mechanisms of action. Plant Lipids Science, Technology, Nutritional Value and Benefits to Human Health 2015: 201-219. 